\title{
Management of Infertility in Endometriosis by Operative Laparoscopy and Medical Therapy-Practiced at 3 Different Centres, from September 2005 to October 2007
}

\author{
Pratibha Devabhaktuni ${ }^{1}$, Swathi Gogineni' ${ }^{1}$, Savitha Devi Yalamanchi'2, Anuradha Katragadda ${ }^{3}$ \\ ${ }^{1}$ Government Maternity Hospital, Nayapul, Institute of Obstetrics and Gynaecology, Osmania Medical College, Hyderabad, India \\ ${ }^{2}$ Swapna Health Care, Hyderabad, India \\ ${ }^{3}$ Anu Infertility Centre, Hyderabad, India \\ Email:dpdnk@yahoo.com
}

How to cite this paper: Devabhaktuni, P., Gogineni, S., Yalamanchi, S.D. and Katragadda, A. (2019) Management of Infertility in Endometriosis by Operative Laparoscopy and Medical Therapy-Practiced at 3 Different Centres, from September 2005 to October 2007. Open Journal of Obstetrics and Gynecology, 9, 775-788.

https://doi.org/10.4236/ojog.2019.96077

Received: April 25, 2019

Accepted: May 30, 2019

Published: June 3, 2019

Copyright $\odot 2019$ by author(s) and Scientific Research Publishing Inc. This work is licensed under the Creative Commons Attribution International License (CC BY 4.0).

http://creativecommons.org/licenses/by/4.0/

\begin{abstract}
This is a prospective study conducted over a period of 2 years and 1 month (from September 2005 to October 2007). 60/117 (52.17\%) patients who had laparoscopy for infertility at GMH had endometriosis. 60 patients operated for endometriosis at SHC and 40 patients managed at Anu Infertility Centre during the same period are also included in this study. All the 60 patients underwent operative laparoscopy for endometriosis. Adhesiolysis, electrocautery of surface endometriosis of the ovary, enucleation of endometriotic cyst, mobilization of ovary from uterus and pouch of Douglas and restoration of normal anatomy were carried out. Treatment interventions: Therapeutic hysteroscopy and laparoscopy, medical treatment by various ovulation induction protocols, monitoring by follicular sonography followed by pregnancy management were done in these women. Results: GMH-Seventeen 17 out of 18 coming for follow up conceived, 14 following ovulation induction and 3 after $\mathrm{COH}+\mathrm{IUI}$, by one year at GMH. SHC -14 out of 18 patients coming for follow up at the end of one year conceived, following ovulation induction 6, $\mathrm{COH}+\mathrm{IUI}-3, \mathrm{IVF}-3$ and spontaneous 2. ANU-Out of 11 conceptions, $\mathrm{COH}+\mathrm{IUI}$ resulted in $6, \mathrm{IVF}$ in 4 , spontaneous in 1 -by one year. Pregnancy outcome: GMH: Ten delivered, Triplets in one, missed abortion two, emergency laparotomy in one. Pregnancy is continuing in 4. SHC: Eight patients delivered. Pregnancy is continuing in 4 patients. Ectopic-1, missed abortion-1. ANU: Five patients delivered. Pregnancy is continuing in 3 women, missed abortion-2, second trimester abruption-1. Discussion: The conception rate was $50 \%$ at the end of 6 months follow up (15 patients conceived out of the 30 who were coming for follow up at the end of 6 months). Fourteen
\end{abstract}


(14) out of the 17 conceptions (82.35\%) occurred following the use of ovulation induction drugs alone. Especially in stages I and II, if ovulation induction can yield conceptions, there is no need to refer to health centres for $\mathrm{COH}$ and IUI as the first option. Conclusions: Operative Hysterolaparoscopy at the same sitting would enable correction of uterine lesions to improve conception rates. From our study at GMH, we conclude that after surgery, simple treatment by ovulation induction alone can result in a high percentage of conceptions within a six-month period.

\section{Keywords}

Endometriosis, Infertility, Conceptions, Ovulation Induction

\section{Introduction}

Endometriosis fertility index (EFI) predicts live births following surgical resection of moderate and severe endometriosis. Live births can accurately be predicted with the endometriosis fertility index (EFI), with adnexal function being the most important factor to predict non-assisted reproductive technology (non-ART) fertility or the requirement for ART. A total of 147 women (63\%) had a live birth following surgery, 94 of them (64\%) without ART [1]. Women with a high EFI score have excellent fertility prognosis and may be advised to try to become pregnant with timed intercourse compared to women with a low score, for which prompt referral to ART seems more reasonable [1].

The Endometriosis Fertility Index takes into account surgical findings both pre-surgery (ASRM scores, essentially amount of disease) and post-surgery (least function score, essentially functional capacity post-resection), and also well known historical factors [2] including age, duration of infertility, and pregnancy history [2].

Ninety-six women of reproductive age who underwent operative laparoscopy to treat endometriosis-related infertility (endometriosis stage I/II $n=67$; stage III/IV $\mathrm{n}=29$ ) from 2001 to 2011 at the Cleveland Clinic Foundation, to determine the fertility benefit of controlled ovarian hyperstimulation $(\mathrm{COH})$ and intrauterine insemination (IUI) in surgically treated endometriosis, $\mathrm{COH}+\mathrm{IUI}$, did not improve pregnancy rates in any stage of endometriosis. In stage III/IV they recommend postoperative in vitro fertilization. Twelve-month cumulative pregnancy rates in stage I/II were $45 \%$ for spontaneous attempts and $42 \%$ for $\mathrm{COH}+\mathrm{IUI}$, and in stage III/IV were $20 \%$ for spontaneous attempts and $10 \%$ for $\mathrm{COH}+\mathrm{IUI}[3]$.

However, for women with a poor EFI score $(\leq 2)$ the chance of pregnancy with expectant management is very low $(0 \%-10 \%)$ and it is most appropriate to refer these women for ART early in the post-operative course to optimize their chance of pregnancy [4] [5]. For women with Stage III-IV endometriosis and an EFI score of $>7$, the chance of non-ART live birth after surgery is $\sim 60 \%$ at 3 years, 
rising to $75 \%$ at 5 years [1].

The endometriosis fertility index (EFI) has been externally validated for prediction of non-ART as well as ART outcomes [5]-[11].

The EFI was the first validated classification to predict spontaneous pregnancy after surgery in endometriotic, infertile, and operated-on patients. It may be a useful new tool to counsel couples for personalized management [5].

In a retrospective study by Nezhat et al. [12] at Stanford University, California, 29 patients with multiple IVF failures underwent laparoscopic treatment for endometriosis. 22 of the 29 patients conceived after laparoscopic treatment. 12 patients conceived spontaneously which included 4 patients with stage IV endometriosis. The high pregnancy rates were attributed to the thorough surgical technique. They have concluded that in the absence of tubal occlusion or severe male factor infertility, laparoscopy may still be considered for the treatment of endometriosis even after multiple IVF failures.

The Eva Littman Study [12] proves that spontaneous conceptions can occur after operative laparoscopy for stage IV endometriosis also without resorting to $\mathrm{GnRH}$ analogues. This has prompted us to conduct the following study and prove that the management of infertility in endometriosis must be individualized.

The question uppermost in mind is: what is the best treatment so that the patients conceive. In this publication, we present our data and suggest some conclusions.

\section{Aims and Objectives}

To study the various modalities of treatment of different stages of endometriosis practiced at 3 different centres-Government Maternity Hospital, Nayapul, (GMH) Hyderabad, Swapna Health Care (SHC) and Anu Infertility Centre, (ANU IC) and to document the conception rates.

We do not have an ART Centre in our hospital. Patients with tubal factor or male factor responsible for their infertility and therefore needing ART were referred to an ART centre.

We have studied the conception rates in endometriosis in an Assisted Reproductive Techniques centre (ART) during our study period which included cases referred from our institute also in addition to others.

\section{Material, Treatment and Observations}

This is a prospective study conducted over a period of 2 years and 1 month (from September 2005 to October 2007. 60/117 (52.17\%) patients operated for infertility at GMH had endometriosis. 60 patients operated for endometriosis at $\mathrm{SNH}$ and 40 patients managed at ANUIC during the same period are also included in this study.

\subsection{Data of Women Managed at GMH}

Total Number of cases 60. Primary infertility-44, Secondary infertility with no 
live child-11, Secondary infertility with one live child-5 (Table $1 \&$ Table 2).

\subsection{Infertility Treatment Prior to Laparoscopy at GMH}

18 patients took some treatment for infertility [ovulation induction, IUI, IVF].

\subsection{Surgical History}

1) One patient underwent laparotomy and bilateral wedge resection of ovaries for endometriotic cysts in 1996. 2) Staging laparotomy was done for bilateral ovarian cysts in one patient. 3) Left ovarian cystectomy and wedge resection of left ovary was done in one patient for haemorrhagic corpus luteal cyst. 4) In one left ovarian cystectomy was done for twisted ovarian cyst. 5) ASD closure was done in one woman at the age of 18 years. 6) And another underwent thyroid surgery 3 years ago.

\subsection{Medical History}

Two patients were treated for tuberculosis-one for pulmonary TB and the other for tuberculous lymphadenitis. Hypothyroidism was present in two, treated, Epilepsy-2, Diabetes-1, Hypertension-1, Heart disease (ASD closure)-1, Previous cytomegalovirus infection-1.

\subsection{Menstrual History}

Menstrual cycles were regular in 46 patients and irregular in fourteen. 15 patients had dysmenorrhoea.

\subsection{Gynae Examination}

Eight patients had adnexal masses on per vaginal examination. (5 were chocolate

Table 1. Age wise distribution of patients in GMH, SNH, ANU IC.

\begin{tabular}{cccc}
\hline Age in years & GMH & SHC & ANU \\
& $\mathrm{N}=60$ & $\mathrm{~N}=60$ & $\mathrm{~N}=40$ \\
\hline Less than 20 & 2 & - & - \\
$21-25$ & 22 & 10 & 6 \\
$26-30$ & 25 & 33 & 23 \\
$31-35$ & 7 & 14 & 10 \\
$36-39$ & 4 & 3 & 1 \\
\hline
\end{tabular}

GMH-Government Maternity Hospital, SHC-Swapna Health Care, ANU IC-Anu Infertility Centre.

Table 2. Duration of infertility.

\begin{tabular}{cccc}
\hline Duration of infertility in years & GMH, N $=60$ & SHC, N $=60$ & ANU, N $=40$ \\
\hline Less than 5 years & 26 & 36 & 21 \\
6 - 10 years & 25 & 18 & 16 \\
More than 11 years & 9 & 6 & 3 \\
\hline
\end{tabular}


cysts at the time of laparoscopy, one was a dermoid cyst, one-a para-ovarian cyst and one was a fibroid). Examination findings were normal in the rest of the patients.

\subsection{Other Salient Investigations}

Hysterosalpingography (HSG) was done in 22 women. Both tubes were patent on HSG in 14 women and unilateral/bilateral tubal blockage was present in eight. CA 125 was done in 8 patients. It was normal in all of them. Four women had hyperprolactinaemia but repeat prolactin levels were normal in two of them. Endometriotic cysts were reported on USG in 8 patients and polycystic ovaries were present in 13 .

Treatment interventions: Therapeutic hysteroscopy and laparoscopy, medical treatment by various ovulation induction protocols, monitoring by follicular sonography followed by pregnancy management were done in these women.

\subsection{Hysteroscopy and Operative Laparoscopy}

Hysteroscopy and operative laparoscopy were done in all infertile patients at the same sitting. Abnormal hysteroscopic findings are shown in Table 3. An endometrial curettage was done at the same sitting to detect endometrial hyperplasia, tuberculosis, abnormalities detected on hysteroscopy would be managed at the same time. Polyp removal, septal resection, synaechiaelysis were done at that time.

Table 3. Endometriosis, in addition, associated factors compromising fertility GMH, SHC, ANU.

\begin{tabular}{|c|c|c|c|c|}
\hline Sl. No & $\begin{array}{l}\text { In addition to endometriosis Associated Factors } \\
\text { Compromising fertility }\end{array}$ & $\begin{array}{c}\mathrm{GMH} \\
\mathrm{N}=60\end{array}$ & $\begin{array}{c}\mathrm{SHC} \\
\mathrm{N}=60\end{array}$ & $\begin{array}{l}\text { ANU IC } \\
\mathrm{N}=40\end{array}$ \\
\hline 1. & Hypothyroidism & 2 & 7 & 3 \\
\hline 2. & $\mathrm{PCO}$ & 13 & 11 & 18 \\
\hline 3. & Hyperprolactinemia & 2 & 2 & 3 \\
\hline 4. & Tuberculosis endometrium & 2 & 1 & - \\
\hline 5. & Diabetes & - & - & 1 \\
\hline 6. & Abnormal hysteroscopic findings & 25 & 12 & 14 \\
\hline 7. & Polyps & 14 & 3 & 5 \\
\hline 8. & Synaechiae & 8 & 1 & 1 \\
\hline 9. & Submucous fibroid & 1 & & \\
\hline 10. & Blocked ostium & 1 & & 2 \\
\hline 11. & Partial uterine septum & 1 & & \\
\hline 12. & Septum uterus & & 5 & 3 \\
\hline 13. & Uterus Duplex + vagina Duplex & & 1 & \\
\hline 14. & Cervical stenosis & & & 2 \\
\hline 15. & Adenomyosis indenting cavity & & 1 & \\
\hline 16. & Pinpoint os & & 1 & 1 \\
\hline
\end{tabular}




\subsection{Histopathological Examination}

Histopathological examination of the endometrial curettings revealed proliferative endometrium in 50 patients, secretory endometrium in 8 and simple cystic hyperplasia in 2 .

\subsection{Staging of Endometriosis at the Time of Laparoscopy}

Accuracy of reporting stage I-IV endometriosis depends also on the subjective assessment. All the patients from three centres underwent operative laparoscopy for endometriosis $[\mathrm{N}=160]$. Adhesiolysis, electrocautery of surface endometriosis of the ovary, enucleation of endometriotic cyst, mobilization of ovary from uterus and poch of Douglas and restoration of normal anatomy were carried out. Methylene blue chromo perturbation was performed in all the cases.

They were advised to come for regular follow up. Those who came for follow up were started on ovulation induction drugs (clomiphene citrate $50 \mathrm{mg}$ OD) from the $2^{\text {nd }}$ day of their cycle for 7 days. Follicular growth was monitored on ultrasonography from the $11^{\text {th }}$ day. Patients were called for post coital test around the time of ovulation (Table $4 \&$ Table 5).

Table 4. Staging of endometriosis at the time of laparoscopy.

\begin{tabular}{cccc}
\hline Stage of endometriosis & GMH N $=60$ & SHC N $=60$ & ANU N $=40$ \\
\hline Stage I & 29 & 16 & 15 \\
Stage II & 20 & 7 & 12 \\
Stage III & 9 & 5 & 5 \\
Stage IV & 2 & 32 & 8 \\
\hline
\end{tabular}

Table 5. Pregnancy rates after laparoscopic management of endometriosis GMH, SHC, ANU.

\begin{tabular}{ccccc}
\hline \multicolumn{2}{c}{$\begin{array}{c}\text { No. of months of } \\
\text { follow up }\end{array}$} & No of conceptions & $\begin{array}{c}\text { No. of patients coming } \\
\text { for follow up }\end{array}$ & \% of conceptions \\
\hline \multirow{3}{*}{3 months } & GMH & 7 & 41 & 17.07 \\
& SHC & 3 & 32 & 9.37 \\
& ANU & 3 & 37 & 8.1 \\
& GMH & 15 & 30 & 50 \\
6 months & SHC & 10 & 25 & 40 \\
& ANU & 9 & 29 & 31.03 \\
& GMH & 16 & 20 & 80 \\
& SHC & 12 & 20 & 60 \\
& ANU & 9 & 24 & 37.50 \\
& GMH & 17 & 18 & 94.44 \\
\hline \multirow{6}{*}{1 year } & SHC & 14 & 18 & 77.77 \\
& ANU & 11 & 15 & 73.33 \\
\hline
\end{tabular}




\section{Treatment Outcomes}

\subsection{Post Operative Treatment}

Post operative hormonal treatment has no beneficial effect on pregnancy rates after surgery.

Only one dose of GnRH analogue was given to two patients. (both of them had stage III endometriosis). One of them conceived. Tab. Danazol $200 \mathrm{mg}$ BD was given for 6 weeks to a patient with stage IV endometriosis as she could not afford GnRH analogues (Table 6).

\subsection{Conceptions with Ovulation Induction [0I], Spontaneous, $\mathrm{COH}+\mathrm{IUI}$ and IVF}

Conceptions in patients coming follow up at the end of one year: Figure 1.

GMH-Seventeen (17) out of 18 coming for follow up conceived, 14 following ovulation induction and 3 after $\mathrm{COH}+\mathrm{IUI}$.

SHC-14 out of 18 patients conceived. Following ovulation induction 6, $\mathrm{COH}$ + IUI-3, IVF-3 and spontaneous 2 .

Table 6. Method of treatment given after operative laparoscopy for endometriosis. Stage wise conception rates in GMH, SHC, ANU infertility centre-2006-2008, Hyderabad.

\begin{tabular}{|c|c|c|c|c|c|c|c|c|c|c|}
\hline \multirow{4}{*}{.No. } & \multicolumn{2}{|l|}{ Method } & \multicolumn{2}{|c|}{ Stage I } & \multicolumn{2}{|c|}{ Stage II } & \multicolumn{2}{|c|}{ Stage III } & \multicolumn{2}{|c|}{ Stage IV } \\
\hline & \multicolumn{2}{|c|}{$\mathrm{GMH}-\mathrm{N}=60$} & GMH 29 & \multirow{3}{*}{ Conceptions } & GMH 20 & \multirow{3}{*}{ Conceptions } & GMH 9 & \multirow{3}{*}{ Conceptions } & GMH 2 & \multirow{3}{*}{ Conceptions } \\
\hline & \multicolumn{2}{|c|}{$\mathrm{SHC}-\mathrm{N}=60$} & SHC 16 & & SHC 7 & & SHC 5 & & SHC 32 & \\
\hline & $\mathrm{ANU}-\mathrm{N}=$ & & ANU 15 & & ANU 12 & & ANU 5 & & ANU 8 & \\
\hline \multirow{3}{*}{1} & \multirow{3}{*}{$\begin{array}{l}\text { Ovulation } \\
\text { induction }\end{array}$} & GMH & 23 & 7 & 16 & 5 & 7 & 2 & 2 & - \\
\hline & & SHC & 12 & 4 & 3 & - & 3 & 1 & 5 & 1 \\
\hline & & ANU & 1 & - & 2 & - & - & - & - & - \\
\hline \multirow{3}{*}{2} & \multirow{3}{*}{$\mathrm{COH}+\mathrm{IUI}$} & GMH & 4 & 3 & 1 & - & - & - & - & - \\
\hline & & SHC & 3 & 2 & - & - & 1 & - & 3 & 1 \\
\hline & & ANU & 13 & 6 & 8 & - & 4 & - & 1 & - \\
\hline \multirow{3}{*}{3} & \multirow{3}{*}{ IVF } & GMH & - & & - & & - & & - & \\
\hline & & SHC & 2 & & - & & - & & 8 & 3 \\
\hline & & ANU & 3 & & 2 & 2 & 1 & & 8 & 2 \\
\hline 4 & ICSI & ANU & - & & 1 & & - & & - & \\
\hline \multirow[t]{2}{*}{5.} & DIPI & ANU & 1 & & 2 & & & & & \\
\hline & & GMH & & & & & & & & \\
\hline \multirow[t]{2}{*}{5.} & Spontaneous & SHC & & & & & & & & 2 \\
\hline & & ANU & & & & & & & & 1 \\
\hline \multirow{3}{*}{5} & & GMH & - & & - & & 2 & & - & \\
\hline & $\begin{array}{l}\text { Post Operative } \\
\text { GnRH analogues }\end{array}$ & SHC & 3 & & 3 & & 2 & & 10 & \\
\hline & & ANU & & & & & & & & \\
\hline
\end{tabular}

Danazol was given to one patient (GMH), Novelon OC pill and Depoprovera (depot medroxy progesterone acetate) were given to one patient each (SHC). 
No. of months of follow up- GMH

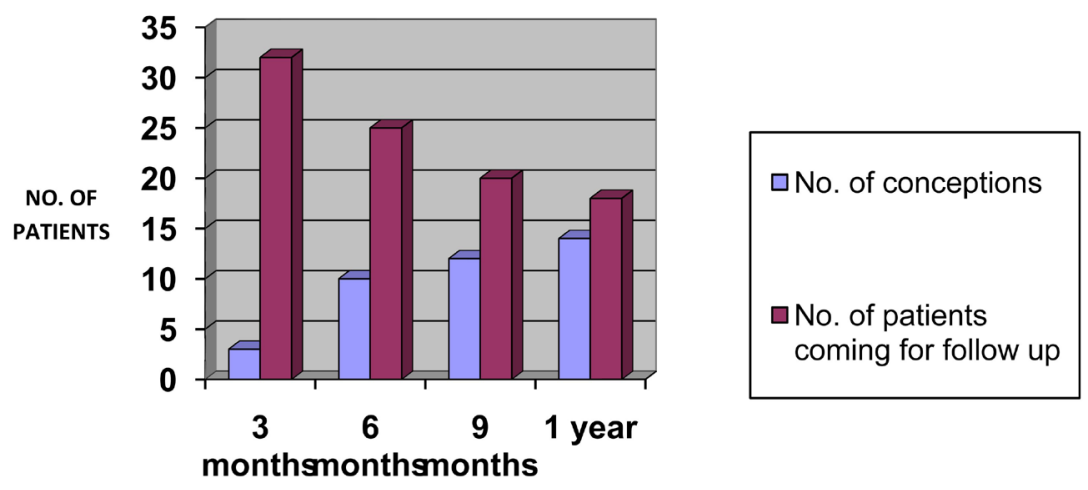

No. of months of follow up- SHC

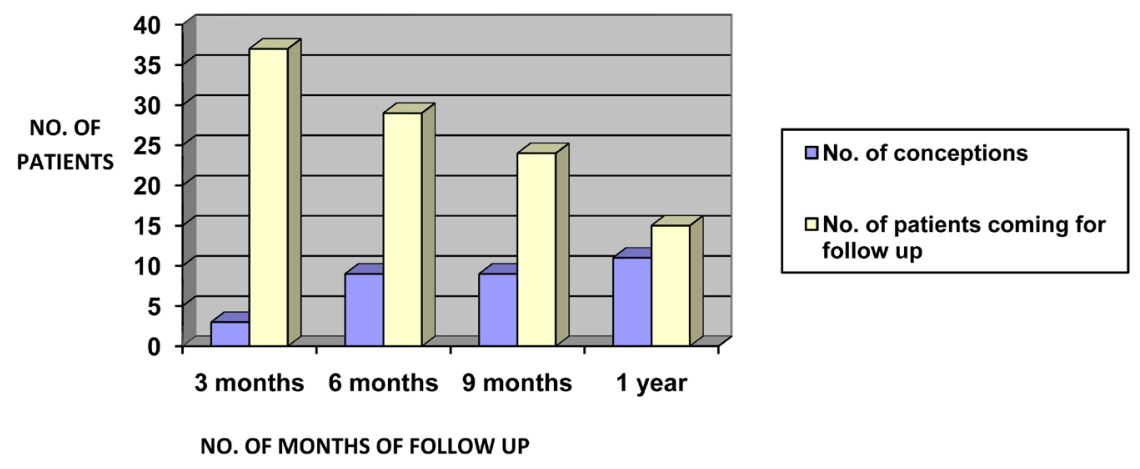

No. of months of follow up- ANU

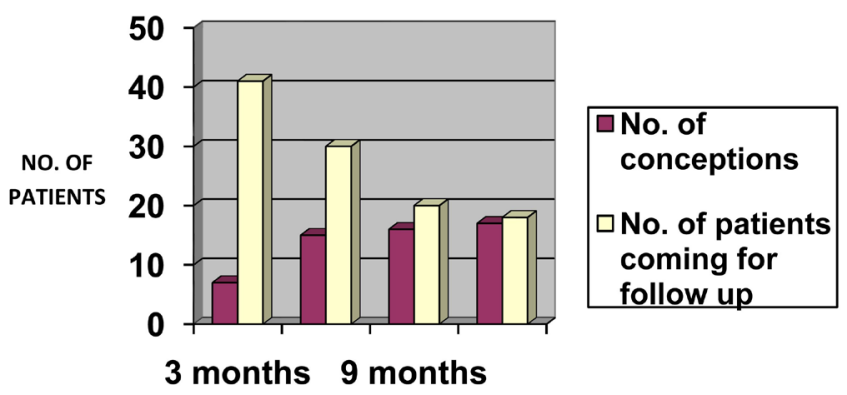

Figure 1. Pregnancy rates after laparoscopic management of endometriosis GMH, SHC, ANU IC.

ANU-Out of 11 conceptions, $\mathrm{COH}+$ IUI resulted in 6, IVF in 4 and spontaneous in 1 (Table 7 \& Table 8).

Patients with male factor as a cause of their infertility, those with tubal factor and those who did not respond to clomiphene citrate were advised to attend ART centre for further management. Most of them could not afford and only 6 went to the ART centre.

\subsection{Endometriosis and ART}

Out of those who came for follow up and did not conceive, only one tube was 
Table 7. Pregnancy rates after laparoscopic treatment of endometriosis [13]. Number of pregnancies/number treated (\%).

\begin{tabular}{|c|c|c|c|c|c|c|c|}
\hline S.No. & Investigator & Stage I & Stage II & Stage III & Stage IV & Combined & $\begin{array}{l}\text { Length of follow } \\
\text { up (months) }\end{array}$ \\
\hline 1 & Eward [14] & $4 / 7(57)$ & $10 / 18(56)$ & - & - & $14 / 25(56)$ & 13 \\
\hline 2 & Hasson [15] & $0 / 1(0)$ & - & $2 / 2(100)$ & $4 / 5(80)$ & $6 / 8(75)$ & 7 \\
\hline 3 & Sulewski et al. [16] & - & $20 / 42(48)$ & $20 / 58(35)$ & - & $40 / 100(40)$ & 37 \\
\hline 4 & Seiler et al. [17] & - & $20 / 45(44)$ & - & - & $20 / 45(44)$ & 7 \\
\hline 5 & Nowroozi et al. [18] & - & $42 / 69(61)$ & - & - & $42 / 69(61)$ & 8 \\
\hline 6 & Daniell \& Pittaway [19] & - & - & - & - & $33 / 60(55)$ & - \\
\hline 7 & Reich \& Mc Glynn [20] & - & - & - & - & $15 / 23(65)$ & 18 \\
\hline 8 & Murphy et al. [21] & $24 / 36(67)$ & $18 / 36(50)$ & 2/7 (29) & $0 / 3(0)$ & $44 / 82(54)$ & 8 \\
\hline 9 & Candiani et al. [22] & - & - & - & $98 / 206(47.6)$ & $98 / 206(47.6)$ & - \\
\hline 10 & Luciano et al. [23] & - & - & $70 \%$ & - & - & - \\
\hline 11 & Busacca et al. [24] & - & - & $57.5 \%$ & - & - & 24 \\
\hline 12 & $\begin{array}{c}\text { GMH Study Dr. D. Pratibha } \\
\text { Dr. G. Swathi }\end{array}$ & 9/17 (52.94) & $5 / 8(62.5)$ & $1 / 4(25)$ & $0 / 1(0)$ & $15 / 30(50)$ & 6 \\
\hline 13 & Swapna nursing home & $4 / 10(40)$ & $0 / 1(0)$ & $1 / 3(33.33)$ & $5 / 11(45.45)$ & $10 / 25(40)$ & 6 \\
\hline 14 & Anu infertility centre & $5 / 13(38.46)$ & $2 / 8(25)$ & $0 / 3(0)$ & $2 / 5(40)$ & 9/29 (31.03) & 6 \\
\hline
\end{tabular}

Table 8. Method of conception GMH- $(n=17)$, SHC $(n=14)$, ANU- $(n=11)$.

\begin{tabular}{|c|c|c|c|c|c|c|c|}
\hline S.No. & \multicolumn{2}{|c|}{ Method } & Total & Stage I & Stage II & Stage III & Stage IV \\
\hline \multirow{3}{*}{1} & \multirow{3}{*}{$\begin{array}{l}\text { Ovulation } \\
\text { Induction } \\
\quad \text { OI }\end{array}$} & $\mathrm{GMH}$ & 14 & 7 & 5 & 2 & - \\
\hline & & SHC & 6 & 4 & - & 1 & 1 \\
\hline & & ANU IC & - & & & & - \\
\hline \multirow{3}{*}{2} & \multirow{3}{*}{$\mathrm{COH}+\mathrm{IUI}$} & GMH & 3 & 3 & - & - & - \\
\hline & & SHC & 3 & 2 & - & - & 1 \\
\hline & & ANU IC & 6 & 6 & & & \\
\hline \multirow{2}{*}{3} & \multirow{2}{*}{ IVF } & SHC & 3 & - & - & - & 3 \\
\hline & & ANU & 4 & - & 2 & - & 2 \\
\hline \multirow{2}{*}{4} & \multirow{2}{*}{ Spontaneous } & SHC & 2 & - & - & - & 2 \\
\hline & & ANU & 1 & & & & 1 \\
\hline
\end{tabular}

patent in 7 women, both tubes were blocked in 3, oligospermia was present in 4 (two of them had grade iii varicocele and one was a known diabetic) and asthenospermia was present in three. Patients with bilateral tubal blockage (3) and those with male factor contributing to infertility (7) were referred to infertility clinic for assisted reproductive techniques. Seven out of these 10 women could not afford and only 3 took treatment at the ART centre (Figure 2).

\subsection{Pregnancy Outcome: Table 9}

GMH: Ten out of the 17 patients delivered. One of them has triplets. All the babies 
Table 9. Endometriosis-pregnancy outcome

\begin{tabular}{cccccc}
\hline Centre & $\begin{array}{c}\text { Total } \\
\text { conceptions }\end{array}$ & Delivered & $\begin{array}{c}\text { Pregnancy } \\
\text { continuing }\end{array}$ & Abortion/Ectopic & $\begin{array}{c}\text { Pregnancy } \\
\text { outcome }\end{array}$ \\
\hline GMH & 17 & 10 & 4 & Missed Abortion-2 & $\begin{array}{c}\text { Emergency } \\
\text { hysterotomy-1 }\end{array}$ \\
SHC & 14 & 8 & 4 & $\begin{array}{c}\text { Ectopic-1, } \\
\text { Abortion-1 }\end{array}$ & \\
ANU IC & 11 & 5 & 3 & Missed abortion-2 & \\
\hline
\end{tabular}

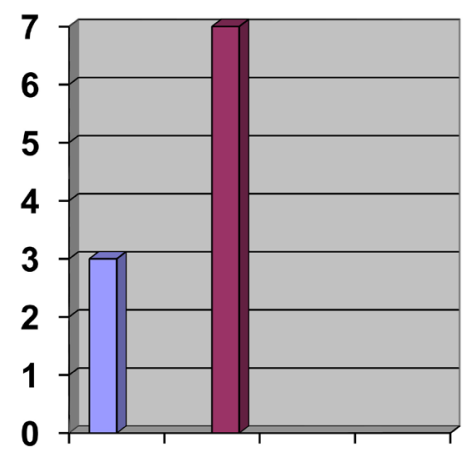

\section{口Both tubes \\ blocked (3) \\ $\square$ Male factor \\ (7)}

Figure 2. Reason for referral to ART-GMH.

survived. Two patients had missed abortion. The abortion rate in our study was $2 / 17(11.76 \%)$ which is the same as in the general population (12\% - 15\%). Emergency hysterotomy was done for a patient in the $6^{\text {th }}$ month for severe preeclampsia and abruption with failure to progress. Pregnancy is continuing in 4 cases.

SHC: Eight patients delivered. One patient had an ectopic pregnancy. Following surgery for ectopic, she conceived spontaneously and had a missed abortion. Pregnancy is continuing in 4 patients.

ANU: Five patients delivered. Two patients had missed abortion. Second trimester pregnancy loss occurred in one. Pregnancy is continuing in 3 women.

\section{Discussion}

The gold standard in the diagnosis of endometriosis is by laparoscopy. The diagnosis of endometriosis-minimal and mild, by USG is difficult and may be missed in the majority of cases.

Operative Hysteroscopy and laparoscopy at the same sitting would enable correction of uterine lesions improving conception rates. Diagnosis of endometriosis as well as management has to be planned at the first laparoscopy to give the maximum benefit to the patient.

Expectant management was not given to any of the patients managed at our institute. All the 60 patients who were diagnosed to have endometriosis at the time of laparoscopy had operative procedure by laparoscopy.

The Canadian Collaborative Group [25] [26] on Endometriosis evaluated the effect of surgical treatment of early stage endometriosis on subsequent fertility. Cumulative pregnancy rates were significantly higher in the group that had un- 
dergone surgical treatment $(30.7 \%$ vs $17.7 \%)$.

In another randomized study, Nowroozi [18] and colleagues evaluated the effect of surgical treatment in 123 women with mild endometriosis. Of the patients in the surgical treatment group, $61 \%$ achieved pregnancy whereas $18.5 \%$ of women who did not receive treatment achieved pregnancy. This difference was significant $(\mathrm{P}<0.001)$.

Post operative hormonal treatment has no beneficial effect on pregnancy rates after surgery. By the time patient resumes normal ovulatory patterns, which may be months after completion of therapy, the deleterious effects of the disease process on fertility that were suppressed initially by medications recur even if the patient remains asymptomatic (RCOG) [27]. GnRH agonists after laparoscopic surgery would delay conception.

Out of 392 analyzed patients, after surgery, 146 couples conceived without ART and 164 with ART (in vitro fertilization [IVF]-intracytoplasmic sperm injection [ICSI]) [5].

A take home baby rate of $59.9 \%$ in ART population, compared with $76 \%$ among patients who obtained an ongoing pregnancy without ART has been reported [5].

After operative laparoscopic surgery for endometriosis, expectant management in cases with high EFI (from 7 to 10), spontaneous pregnancy could be favored [5] [28].

An average pregnancy rate of $41.9 \%$, (18/43 patients) through natural conception has been reported during the first year after laparoscopic surgery in infertile women with endometriosis and no other factors, without ART or hormone treatment (stage I, 35.7\%; stage II, 44.4\%; stage III, 53.3\%; and stage IV 20.0\%) [29].

Seventy-eight women diagnosed with severe endometriosis during surgery (AFS 3 - 4) with multiple failed IVF treatments before surgery, had (42.3\%) 33 conceptions after surgical treatment, following ART and delivered [30].

The success rates following ART and spontaneous conceptions after laparoscopic surgery signal that there is light at the end of the tunnel.

In our study from GMH, the conception rate was $50 \%$ at the end of 6 months follow up (15 patients conceived out of the 30 who were coming for follow up at the end of 6 months).

Fourteen (14) out of the 17 conceptions (82.35\%) occurred following the use of ovulation induction drugs alone.

From all three centres, by the end of 6 months, $34 / 84$ patients, $40.47 \%$ conceived, 42 out of 50 coming for follow up [84\%] conceived by one year.

IVF is the appropriate treatment especially if tubal function is compromised, if there is also male factor infertility and/or other treatments have failed [27].

\section{Conclusions}

Hysteroscopy and laparoscopy (hysterolap.) at the same sitting would enable 
correction of uterine lesions, to improve conception rates.

Adequate surgical treatment by laparoscopy would improve conception rates. Diagnosis of endometriosis as well as management has to be planned at the first laparoscopy to give the maximum benefit to the patient.

From our study at GMH, we conclude that after surgery, simple treatment by ovulation induction alone can result in a high percentage of conceptions within a six-month period. The longer the interval to conception, dropout rate would increase, especially in the Indian scenario where family pressure to consult another doctor would be more.

Especially in stages I and II, if ovulation induction can yield conceptions, there is no need to refer to health centres for $\mathrm{COH}$ and IUI as the first option.

\section{Acknowledgements}

I wish to express my sincere thanks to Dr. P. Balamba, for referring women with infertility needing laparoscopic evaluation to Government Maternity Hospital, when I informed her regarding our endometriosis study.

\section{Conflicts of Interest}

The authors declare no conflicts of interest regarding the publication of this paper.

\section{References}

[1] Maheux-Lacroix, S., Nesbitt-Hawes, E., Deans, R., Won, H., Budden, A., Adamson, D. and Abbott, J.A. (2017) Endometriosis Fertility Index Predicts Live Births Following Surgical Resection of Moderate and Severe Endometriosis. Human Reproduction, 32, 2243-2249. https://doi.org/10.1093/humrep/dex291

[2] Collins, J.A., Burrows, E.A. and Willan, A.R. (1995) The Prognosis for Live Birth among Untreated Infertile Couples. Fertility and Sterility, 64, 22-28. https://doi.org/10.1016/S0015-0282(16)57650-X

[3] Gandhi, A.R., Carvalho, L.F., Nutter, B. and Falcone, T. (2014) Determining the Fertility Benefit of Controlled Ovarian Hyperstimulation with Intrauterine Insemination after Operative Laparoscopy in Patients with Endometriosis. The Journal of Minimally Invasive Gynecology, 21, 101-108. https://doi.org/10.1016/j.jmig.2013.07.009

[4] Adamson, G.D. and Pasta, D.J. (2010) Endometriosis Fertility Index: The New, Validated Endometriosis Staging System. Fertility and Sterility, 94, 1609-1615. https://doi.org/10.1016/j.fertnstert.2009.09.035

[5] Boujenah, J., Bonneau, C., Hugues, J.N., Sifer, C. and Poncelet, C. (2015) External Validation of the Endometriosis Fertility Index in a French Population. Fertility and Sterility, 104, 119-123. https://doi.org/10.1016/j.fertnstert.2015.03.028

[6] Wei, D.-M., Yu, Q., Sun, A.-J., Tian, Q.-J., Chen, R., Deng, C.-Y., Sun, Z.-Y., Zhen, J.-R. and He, F.-F. (2011) Relationship between Endometriosis Fertility Index and Pregnancies after Laparoscopic Surgery in Endometriosis-Associated Infertility. Chinese Journal of Obstetrics and Gynecology, 46, 806-808.

[7] Tomassetti, C., Geysenbergh, B., Meuleman, C., Timmerman, D., Fieuws, S. and D'Hooghe, T. (2013) External Validation of the Endometriosis Fertility Index (EFI) 
Staging System for Predicting Non-ART Pregnancy after Endometriosis Surgery. Human Reproduction, 28, 1280-1288. https://doi.org/10.1093/humrep/det017

[8] Wang, W., Li, R., Fang, T., Huang, L., Ouyang, N., Wang, L., Zhang, Q. and Yang, D. (2013) Endometriosis Fertility Index Score Maybe More Accurate for Predicting the Outcomes of in Vitro Fertilisation than r-AFS Classification in Women with Endometriosis. Reproductive Biology and Endocrinology, 11, 112.

https://doi.org/10.1186/1477-7827-11-112

[9] Zeng, C., Xu, J.-N., Zhou, Y., Zhou, Y.-F., Zhu, S.-N. and Xue, Q. (2014) Reproductive Performance after Surgery for Endometriosis: Predictive Value of the Revised American Fertility Society Classification and the Endometriosis Fertility Index. $G y^{-}$ necologic and Obstetric Investigation, 77, 180-185.

https://doi.org/10.1159/000358390

[10] Garavaglia, E., Pagliardini, L., Tandoi, I., Sigismondi, C., Viganò, P., Ferrari, S. and Candiani, M. (2015) External Validation of the Endometriosis Fertility Index (EFI) for Predicting Spontaneous Pregnancy after Surgery: Further Considerations on Its Validity. Gynecologic and Obstetric Investigation, 79, 113-118. https://doi.org/10.1159/000366443

[11] Ibrjam, I., Veleva, G., Karagjozova, G. and Ivanov, S. (2016) Endometriosis Fertility Index. Akusherstvo i Ginekologiāà(Sofiia), 55, 5-10.

[12] Littman, E., Giudice, L., Lathi, R., Berker, B., Milki, A. and Nezhat, C. (2005) Role of Laparoscopic Treatment of Endometriosis in Patients with Failed in Vitro Fertilization Cycles. Fertility and Sterility, 84, 1574-1578. https://doi.org/10.1016/j.fertnstert.2005.02.059

[13] Wallach, E.E., Cook, A.S. and Rock, J.A. (1991) The Role of Laparoscopy in the Treatment of Endometriosis. Fertility and Sterility, 55, 663-680. https://doi.org/10.1016/S0015-0282(16)54228-9

[14] Eward, R.D. (1978) Cauterization of Stages I and II Endometriosis and the Resulting Pregnancy Rate. In: Phillips, J.M., Ed., Endoscopy in Gynecology: The Proceedings of the Third International Congress on Gynecologic Endoscopy, American Association of Gynecologic Laparoscopists, Downey, CA.

[15] Hasson, H.M. (1979) Electrocoagulation of Pelvic Endometriotic Lesions with Laparoscopic Control. American Journal of Obstetrics \& Gynecology, 135, 115-121.

[16] Sulewski, J.M., Curcio, F.D., Bronitsky, C. and Stenger, V.G. (1980) The Treatment of Endometriosis at Laparoscopy for Infertility. American Journal of Obstetrics \& Gynecology, 138, 128-132. https://doi.org/10.1016/0002-9378(80)90022-8

[17] Seiler, J.C., Gidwani, G. and Ballard, L. (1986) Laparoscopic Cauterization of Endometriosis for Fertility: A Controlled Study. Fertility and Sterility, 46, 1098-1100. https://doi.org/10.1016/S0015-0282(16)49887-0

[18] Nowroozi, K., et al. (1987) Randomized Trial of Laparoscopic Electro Coagulation and No Therapy in Endometriosis. In: Kovacs, G.T., Ed., The Subfertility Handbook, A Clinician's Guide, Cambridge University Press, Cambridge.

[19] Daniell, J.F. and Pittaway, D.E. (1982) Use of the $\mathrm{CO}_{2}$ Laser in Laparoscopic Surgery: Initial Experience with the Second Puncture Technique. Infertility, 5, 15.

[20] Reich, H. and McGlynn, F. (1986) Treatment of Ovarian Endometriomas Using Laparoscopic Surgical Techniques. The Journal of Reproductive Medicine, 31, 577-584.

[21] Murphy, A.A., Green, W.R., Bobbie, D., dela Cruz, Z.C. and Rock, J.A. (1986) Unsuspected Endometriosis Documented by Scanning Electron Microscopy in Visually Normal Peritoneum. Fertility and Sterility, 46, 522-524. 
https://doi.org/10.1016/S0015-0282(16)49598-1

[22] Candiani, G., Vercellini, P., Fedele, L., Biandi, S., Vendola, N. and Candiani, M. (1991) Conservative Surgical Treatment for Severe Endometriosis in Infertile Women: Are We Making Progress? Obstetrical \& Gynecological Survey, 46, 490-498. https://doi.org/10.1097/00006254-199107000-00029

[23] Luciano, A.A., Lowney, J. and Jacobs, S.L. (1992) Endoscopic Treatment of Endometriosis Associated Infertility; Therapeutic, Economic and Social Benefits. The Journal of Reproductive Medicine, 37, 573-576.

[24] Busacca, M., Bianchi, S., Agnoli, B., Candiani, M., Calia, C., De Marinis, S. and Vignali, M. (1999) Follow Up of Laparoscopic Treatment of Stage III-IV Endometriosis. Journal of the American Association of Gynecologic Laparoscopists, 6, 655-658.

[25] Marcoux, S., Maheux, R. and Berube, S. (1997) Laparoscopic Surgery in Infertile Women with Minimal or Mild Endometriosis. Canadian Collaborative Group on Endometriosis. The New England Journal of Medicine, 337, 217-222. https://doi.org/10.1056/NEJM199707243370401

[26] Bérubè, S., Marcoux, S., Langevin, M. and Meheux, R. (1998) Fecundity of Infertile Women with Minimal or Mild Endometriosis and Women with Unexplained Infertility. Fertility and Sterility, 69, 1034-1041. https://doi.org/10.1016/S0015-0282(98)00081-8

[27] RCOG (2006) Green-Top Guideline No. 24.

[28] Nesbitt-Hawes, E.M., Campbell, N., Maley, P.E., et al. (2015) The Surgical Treatment of Severe Endometriosis positively Affects the Chance of Natural or Assisted Pregnancy Postoperatively. BioMed Research International, 2015, Article ID: 438790. https://doi.org/10.1155/2015/438790

[29] Lee, H.J., Lee, J.E., Ku, S.-Y., Kim, S.H., Kim, J.G., Moon, S.Y. and Choi, Y.M. (2013) Natural Conception Rate Following Laparoscopic Surgery in Infertile Women with Endometriosis. Clinical and Experimental Reproductive Medicine, 40, 29-32. https://doi.org/10.5653/cerm.2013.40.1.29

[30] Soriano, D., Adler, I., Bouaziz, J., Zolti, M., Eisenberg, V.H., Goldenberg, M., Seidman, D.S. and Elizur, S.E. (2016) Fertility Outcome of Laparoscopic Treatment in Patients with Severe Endometriosis and Repeated in Vitro Fertilization Failures. Fertility and Sterility, 106, 1264-1269.

https://doi.org/10.1016/j.fertnstert.2016.06.003 